\begin{tabular}{|c|l|}
\hline Title & Environmental magnetic approach towards the quantification of pollution in Kathmandu urban area, Nepal \\
\hline Author(s) & Gautam, Pitambar; Blaha, Ulrich; A ppel, Erwin; Neupane, Ghanashy am \\
\hline Citation & $\begin{array}{l}\text { Physics and chemistry of the earth, 29(13-14), 973-984 } \\
\text { https://doi.org/10.1016/.pce.2004.02.001 }\end{array}$ \\
\hline Issue Date & 2004 \\
\hline Doc URL & http://hdl.handle.net/2115/38428 \\
\hline Type & article (author version) \\
\hline File Information & gautam-2.pdf \\
\hline
\end{tabular}

Instructions for use 


\title{
Environmental magnetic approach towards the quantification of pollution in Kathmandu urban area, Nepal
}

Pitambar Gautam ${ }^{\mathrm{a}, \mathrm{c}, *}$, Ulrich Blaha $^{\mathrm{b}}$, Erwin Appel ${ }^{\mathrm{b}}$, Ghanashyam Neupane ${ }^{\mathrm{c}}$

${ }^{a}$ COE Office for Neo-Science of Natural History, N222 Faculty of Science, Hokkaido University N10 W8, Sapporo 060-0810, Japan

${ }^{b}$ Institute of Geosciences, University of Tübingen, 72076 Tübingen, Germany

${ }^{c}$ Central Department of Geology, Tribhuvan University, Kirtipur, Kathmandu, Nepal

*Corresponding author.

Address for correspondence: COE Office for Neo-Science of Natural History, N222 Faculty of Science, Hokkaido University N10 W8, Sapporo 060-0810, Japan

E-mail:p-gautam@nature.sci.hokudai.ac.jp,pgautam2000@yahoo.com

FAX: +81 117062986

\begin{abstract}
The Kathmandu Valley is a bowl-shaped intermontane basin, which occupies an area of $583 \mathrm{~km}^{2}$ in the heart of the Himalayas, with its floor at ca. $1400 \mathrm{~m}$ and the surrounding mountains attaining a height of $2000-2800 \mathrm{~m}$. It is inhabited by ca. 1.5 million people, concentrated mostly in three cities, Kathmandu, Patan and Bhaktapur. Due to rapid but uncontrolled urbanization and factors such as traffic movement, emissions from brick-kilns, cement factory, other industrial activities, waste disposal and biomass burning, environmental pollution has been constantly increasing adversely affecting land, water, air and biological systems.
\end{abstract}

In order to quantify the degree of environmental pollution using magnetic methods, magnetic susceptibility of soils, sediments and roadside material, in and outside the Kathmandu urban areas, has been measured. In areas far from roads or industry, median susceptibility is $(3-35) \times 10^{-5}$ SI which is similar to that observed in the valley-filling clastic sediments being consistent with geologic or pedogenic origin. In traverses across roads, a 5-m wide zone situated at either sides of the asphalt-paved road exhibits a susceptibility enhancement zone with maximum susceptibility of $240-850 \times 10^{-5} \mathrm{SI}$ occurring $0.5-2.5 \mathrm{~m}$ from the road edge. In urban recreational areas, it varies within a broad range ( 3 to $>100 \times 10^{-5} \mathrm{SI}$ ) with the lowest values occurring about $50 \mathrm{~m}$ from any surrounding roads in areas least disturbed by human activity. A systematic increase in susceptibility towards the roads or industrial sites is observed. Within urban areas, in the 
vicinity of heavy traffic or industrial sites, the upper $30-50 \mathrm{~cm}$ of soil profiles exhibit frequent enhancement in susceptibility, of one or two orders of magnitude higher than those expected from geologic input. Such enhancements are attributed to input from anthropogenic or industrial sources. Magneto-mineralogical analyses and scanning electron microscopy on magnetic extracts, grain size fractions or bulk samples of road dust and soils suggest lithogenic magnetite-like minerals and anthropogenic magnetic spherules to be the dominant contributors to the susceptibility signal.

As the soils, sediments and roadside material exhibit significant susceptibility contrasts, which are most effective in identifying traffic-related pollution "hotspots", it is highly desirable that the potential of susceptibility maps of the entire area affected by urbanization, be fully explored to assess the status of environmental degradation.

Keywords: Environmental pollution; Kathmandu; Magnetic susceptibility; Environmental magnetism; Magnetic spherules

\section{Introduction}

Environmental magnetic methods based on the study of variations in magnetic susceptibility and rockmagnetic parameters have been successfully used over several decades to characterize and quantify the degree of pollution of air, water vegetation and land systems (Petrovsky and Ellwood, 1999). The effective use of these methods in studying the urban pollution has been shown by more recent studies (e.g., Hoffmann et al., 1999; Matzka and Maher, 1999; Shu et al., 2000; Knab et al., 2001; Hanesch and Scholger, 2002; Muxworthy et al., 2002). These facts prompted us to undertake joint magnetic and geochemical investigations of urban materials (soil, road dust and tree-leaves) to address the environmental pollution of Kathmandu city, that has been subjected to environmental stress due to population overpressure and related urbanization. The factors responsible for the pollution are uncontrolled traffic movement and related vehicular pollution, emissions from the Himal cement factory (existing until 2000) and brick kilns, industrial activities and biomass burning (Shrestha and Pradhan, 2000; Devkota, 2001; Malinovsky, 2001; NESS, 2001; Shrestha and Raut 2002).

The Kathmandu Valley is situated within the Lesser Himalaya and is filled by fluvial and lacustrine sediments, of Plio-Pleistocene age, derived from the north and north-east and surrounding metasedimentary terrains (Yoshida and Gautam, 1988; Sakai et al., 2002). The high concentration of atmospheric particulate matter is of serious concern in Kathmandu Valley. The high amount of atmospheric dust partly arises from the fact that 
the bowl-shaped valley (with its height of up to 1,500 m) is an effective trap for dust material reworked from the heavily cultivated land. In 1999 to 2000, the 24-hour averages of particulate matter of size less than 10 micron $\left(\mathrm{PM}_{10}\right)$ and total suspended particulate (TSP) ranges were $49-495 \mu \mathrm{g} / \mathrm{m}^{3}$ and $61-572 \mu \mathrm{g} / \mathrm{m}^{3}$, respectively. Also a direct relationship between the atmospheric particulate matter concentration and the degree of urbanization was seen (NESS, 2001). According to an inventory in 2001, the total annual $\mathrm{PM}_{10}$ and TSP loads in Kathmandu Valley amounted to 7580 and 19,885 tons, respectively, with $67 \%$ of the $\mathrm{PM}_{10}$ load believed to arise from vehicular emissions (Shrestha and Raut, 2002).

Recent studies point out that emission from the brick kilns alone contributes to a quarter of the $\mathrm{PM}_{10}$ concentration in the Kathmandu Valley (Raut, 2003). About $90 \%$ of the brick kilns operating in Kathmandu Valley are of the so-called Bull's trench type - an arch-less version of the Hoffmann kiln designed by W. Bull, a British engineer, toward the end of the $19^{\text {th }}$ century. Though these kilns have advantages of low cost of construction and comparatively low specific energy consumption $\left(1.2-1.75 \mathrm{MJ} \mathrm{kg}^{-1}\right)$ they produce a high amount of smoke as the fuel used is any combustible material or a combination of coal, lignite, peat, firewood, saw dust or agricultural waste (such as rice husks).

Detailed are the results of magnetic susceptibility measurements aimed at defining a mapping strategy of the whole Kathmandu urban area (Fig. 1). We conducted a preliminary in situ soil susceptibility survey as follows:

(i) Profiling along relatively long traverses encompassing both urban as well as peripheral parts. Short profiles across roads of varying categories, combined with meter-scale vertical soil sections.

(ii) Mapping of areas $0.02-0.6 \mathrm{~km}^{2}$, located within both seemingly unpolluted areas, far away from the urban areas, as well as the recreational parks in the vicinity of urban and industrial areas that are susceptible to pollution. Besides susceptibility, magneto-mineralogical, microscopic and chemical composition of magnetic minerals, to characterize the urban material, are also described.

$\rightarrow$ Fig. 1

\section{Research Methodology}

Measurements of the low-field magnetic susceptibility of the top-soil or ground (hereafter in situ susceptibility) were conducted at discrete points along profiles (lateral or vertical), or over selected areas, using either a Bartington Ltd. MS2D or MS2F meter 
or a pocket susceptibility WSLA meter made by Aerogeophysical Survey of China. The MS2D and MS2F loop sensors operate at frequencies of $958 \mathrm{~Hz}$ and $580 \mathrm{~Hz}$, respectively, and their average diameters are $185 \mathrm{~mm}$ and $15.5 \mathrm{~mm}$, respectively (Dearing, 1999). For MS2D, 95\% of the susceptibility signal comes from the upper 80 $\mathrm{mm}$ of the subsurface and the integrated volume corresponds to $4300 \mathrm{~cm}^{3}$ (Lecoanet et al., 1999). According to the manuals, the depth of penetration for MS2F is about $15 \mathrm{~mm}$ from the tip of the sensor. The sensitivity of both MS2D and MS2F probes is about $2 \mathrm{x}$ $10^{-6} \mathrm{SI}$. The WSLA probe, with a diameter of $34 \mathrm{~mm}$ and sensitivity of $1 \times 10^{-5} \mathrm{SI}$, has a relatively larger depth of penetration compared to MS2F.

Cores of $3.5 \mathrm{~cm}$ diameter (obtained by vertically inserting a $30-\mathrm{cm}$ long hollow pipe into the ground) and $2.54 \mathrm{~cm}$ diameter (10 cc in volume) were sampled in the field. In the laboratory, the former were measured on a Bartington MS2C meter, with operating frequency of $565 \mathrm{~Hz}$, internal sensor diameter of $40 \mathrm{~mm}$, and sensitivity of $2 \times 10^{-6} \mathrm{SI}$, for volume susceptibility (hereafter susceptibility or $\mathrm{k}$ ). The susceptibility of the latter was measured on the AGICO KLY-2 Kappabridge, with an operating frequency of 920 $\mathrm{Hz}$ and sensitivity of $4 \times 10^{-8} \mathrm{SI}$, and normalized by the sample mass to obtain the mass-specific susceptibility (hereafter mass susceptibility or $\chi$ ).

Samples of road dust were collected from a $2 \mathrm{~m}^{2}$ area at the rim of the road using a nylon brush and plastic container. Large particles (such as stones, brick pieces and other detrital material) and organic matter were removed at the spot. In the laboratory, the samples were dried at $75^{\circ} \mathrm{C}$ for 24 hours. The dried samples were then separated using analytical sieves into a bulk sample (particle diameter $<2 \mathrm{~mm}$ ) and size fractions of 0.2 $-0.63 \mathrm{~mm}$ (coarse), $0.063-0.2 \mathrm{~mm}$ (medium) and $<0.063 \mathrm{~mm}$ (fine).

The variation of susceptibility with temperature $\left(-194^{\circ} \mathrm{C}\right.$ to $0^{\circ} \mathrm{C}$ and $40^{\circ} \mathrm{C}$ to $\left.700^{\circ} \mathrm{C}\right)$ was recorded for small specimens (ca. $0.25 \mathrm{~cm}^{3}$ ) of soil and road dust using the AGICO KLY-3 Kappabridge, which operates at $875 \mathrm{~Hz}$ and has a sensitivity of $3 \times 10^{-8}$ SI, with an attached CS-3 furnace. Experiments were conducted in air and the measurement interval was $2.5^{\circ} \mathrm{C}$ with a heating rate of $10^{\circ} \mathrm{C} / \mathrm{min}$.

The Characteristic temperatures related to Curie points or mineral phase decomposition, inversion or transition are estimated in different ways. (a) Determination of Curie/Neel temperatures from thermomagnetic curves using the method of tangents (Moskowitz, 1981) and the second derivative (Tauxe, 1998), which have been traditionally used also for susceptibility curves, and (b) Detection of the temperature at which the inverse susceptibility starts to change linearly with temperature following the Curie-Weiss law 
applicable for paramagnetic material (Petrovsky and Kapička, 2003). The temperature marking the beginning of the paramagnetic behaviour, in this latter method, also marks the end of the spontaneous ferromagnetic behaviour and serves as marking of Curie or Neel temperature. Exact determination of the relatively short linearity range (generally $<100{ }^{\circ} \mathrm{C}$ ) by using strict numerical criteria for linearity seemed to be difficult because of a quasi-periodic high frequency noise superposed on a weak signal (see Figs. 8, 9). Therefore, the starting point of the linear sector is estimated by judging the line-fit by eye.

Samples of $10 \mathrm{cc}$ volume were subjected to isothermal remanent magnetization (IRM) acquisition up to a maximum of $2.5 \mathrm{~T}$, using pulse fields at $18-20$ steps generated by a Magnetic Measurements pulse magnetizer. The acquired IRM moment was measured by a Molspin spinner magnetometer. The IRM curves were analysed using cumulative lognormal Gaussian decomposition techniques to discriminate the contribution of magnetic materials with differing coercivity spectra (Kruiver et al., 2001).

Magnetic extracts of some samples were isolated by using a hand magnet. These extracts were coated with carbon and observed using a scanning electron microscope (Leo SEM 1450VP). Major element composition of selective grains was measured with an Oxford INCA EDS 200 microanalysis system linked to SEM and run at an accelerating voltage of $15 \mathrm{kV}$, a beam current of $250 \mathrm{pA}$ and counting time of $60 \mathrm{~s}$ per element. Quantification is based on the internal default standard calibration using the strobe peak function and the XPP correction model (Pouchou and Pichoir, 1991). Results were normalized by preset $\mathrm{O}$-stoichiometry (total iron $\mathrm{Fe}^{2+}$ as $\mathrm{FeO}_{\text {tot }}$, $\mathrm{Al}$ as $\mathrm{Al}_{2} \mathrm{O}_{3}$, $\mathrm{Si}$ as $\mathrm{SiO}_{2}$ and $\mathrm{Co}$ as $\mathrm{CoO}$ ).

\section{Magnetic Susceptibility Data}

\subsection{Lateral profiling}

A greater than 4-km long in situ susceptibility profile approaching the Ring Road from outskirts in Machhegaon is shown in Fig. 2. The median in situ susceptibility along the profile varies between $3 \times 10^{-5} \mathrm{SI}$ and $60.5 \times 10^{-5} \mathrm{SI}$ with a log-normal mode of $8.3 \mathrm{x}$ $10^{-5} \mathrm{SI}$. Most values lie within $2-20 \times 10^{-5} \mathrm{SI}$, which is typical for the fluvio-lacustrine sediments constituting the study area. Within the first $500 \mathrm{~m}$ of the profile, located close to active brick-kilns, in situ susceptibility is in excess of 10 and it seems to correlate to topography with larger value on the higher ground. Sometimes, large local variations of in situ susceptibility were observed in dry agricultural fields which are lacking in irrigation. These variations may arise due to differences in the effect of biomass burning, fertilizer usage or natural soil variability. 
In situ susceptibility across roads differing in width and traffic density are illustrated in Fig. 3. Compared to the peripheries of the city, these variations are much more pronounced along road traverses closer to or in the urban area. A relatively high in situ susceptibility characterizes the asphalt-paved portion of any road corridor. However, higher in situ susceptibility values at a distance of $0.5-2.5 \mathrm{~m}$ away from the paved road edge reaching $850 \times 10^{-5} \mathrm{SI}$ are observed. Decay of in situ susceptibility to the background value of ca. $10 \times 10^{-5} \mathrm{SI}$ occurs within about $5 \mathrm{~m}$ of the road edge. The decay of the in situ susceptibility anomalies away from the road is generally monotonous and exponential with respect to the distance. In addition, there is asymmetry in anomaly with respect to the road axis as the anomalous zone opposite to the prevailing wind direction is wider and more intense in traverses such as Bafal (Fig. $3 b$ ), where the wind blows from WSW. These characteristics are similar to in situ susceptibility studies for the Tübingen area (Hoffmann et al., 1999) and can be attributed to the traffic pollution producing vehicular engine emissions, dust from the braking system, and abrasion of the asphalt. For some road profiles in Tübingen, a positive correlation of the lateral and vertical (down to a depth of $1 \mathrm{~m}$ ) variations of susceptibility with contents of heavy metals $(\mathrm{Cd}, \mathrm{Cu}, \mathrm{Zn}$, and $\mathrm{Pb}$ attributable to automotive sources) in soil samples has been well established (Hoffmann et al., 1999; Knab et al., 2001). We infer that the localized, narrow and linear configuration of in situ susceptibility enhancement parallel to the road alignment results from the deposition of traffic-related particles. These particles accumulate in the close vicinity of the road immediately after discharge into the environment as described by Petrovsky and Ellwood (1999).

$\rightarrow$ Fig. 3

\subsection{Mapping}

Within the urban area, relatively small areas, of $0.02-0.6 \mathrm{~km}^{2}$, and recreational parks, which were seemingly less polluted, were mapped in detail. In order to demonstrate the in situ susceptibility variation, we present data from Ratna Park, situated at the city center, and Kirtipur Park situated ca. $1 \mathrm{~km}$ away from the Ring Road and outside the urban area with heavy traffic.

Within Ratna Park, median susceptibility lies within the range $3-155 \times 10^{-5}$ SI. The lowest values occur more than $50 \mathrm{~m}$ from roads. A systematic increase of susceptibility 
towards the roads is observed (Fig. 4a). The susceptibility data from Ratna Park show a multimodal distribution (Fig. 4b). The bimodal logarithmic distribution yields modes of $15 \times 10^{-5} \mathrm{SI}$ (the local background) and $83 \times 10^{-5} \mathrm{SI}$ that is biased by anthropogenic input of magnetic material related to vehicular emission (Fig. 4b).

\section{$\rightarrow$ Fig. 4a,b}

In Kirtipur Park area, susceptibility varies from 2 to greater than $100 \times 10^{-5} \mathrm{SI}$ (Fig. 4c). Here again, areas lying more than $100 \mathrm{~m}$ from road or built-up areas surrounding the park have a very low susceptibility of $2-8 \times 10^{-5}$ SI. The rapid increase in susceptibility is observed approaching roads or built-up areas or sites with construction material debris.

\section{$\rightarrow$ Fig. 4c}

\subsection{Vertical soil and sediment profiles}

\subsubsection{Background areas}

A two-m deep soil profile from Balkhu, downstream from the bridge at the Ring Road is shown in Fig. 5a (site B in Fig. 1d). The fluvial sediment sequence, of Pleistocene age (Yoshida and Gautam, 1988), has no signs of present-day environmental pollution and soil development. The in situ susceptibility has a range of $2-27 \times 10^{-5}$ SI showing an approximate inverse relationship with the grain size. Thin yellowish layers (up to $2 \mathrm{~cm}$ thick) rich in Fe-Mn oxides or hydroxides give rise to locally high susceptibilities within lithologicaly distinct layers, e.g. at $97 \mathrm{~cm}$ and $131 \mathrm{~cm}$ (Fig. 5a). This profile serves as a guide to the lithogenic background susceptibility in the Kathmandu basin.

The susceptibility profile at a paddy field site ( $\mathrm{K}$ in Fig. 1d) in Kirtipur close to the Tribhuvan University Campus with soil of silty clay is shown in Fig. 5b. Though it has no layered structure, light gray and dark gray domains caused by varying silt to clay ratio and moisture content were seen. The upper ca. $30 \mathrm{~cm}$ of the soil is manually reworked at least twice a year prior to cultivation of rice and other crops (such as potato, mustard and wheat). Measurements on long cores yield susceptibility value of less than $20 \times 10^{-5}$ SI except at several levels, characterized by yellowish grey lenses showing values up to $60 \times 10^{-5} \mathrm{SI}$ (Fig. 5b). Values of mass susceptibility based on short diameter cores, sampled separately from the same profile, yield more consistent values. Anomalies caused by thin individual layers or lenses are clearly recognized in both volume and mass susceptibility data (Fig. 5b). 


\subsubsection{Recreational park sites close to urban and industrial areas}

The soil profiles shown in Fig. 6 are dominated by silt or sand, occasionally containing gravel, rock fragments and pieces of baked and unbaked brick, the most common traditional construction material in Kathmandu. Most of the soil material seems to have been transported from elsewhere or reworked during landscaping and gardening (before or during the 1960's, prior to the commencement of industry or heavy traffic) such that no natural soil profile of layered soil structure is seen. In most sites, the upper $30-50$ $\mathrm{cm}$ interval exhibits frequent enhancement of susceptibility, 10 to 100 times larger than those expected from natural soils. The thin and erratic susceptibility highs correspond mostly to the localized brick fragments. Broader susceptibility highs, such as that above $10 \mathrm{~cm}$ in $\mathrm{Hx} 8$ (Fig. 6), are believed to result from material related to vehicular pollution or industry-related activities.

$\rightarrow$ Fig. 6

\section{Magnetic mineralogy}

\subsection{Isothermal remanent magnetization acquisition}

The IRM acquisition curves for road dusts of bulk samples and its different-sized fractions (Fig. 7) are best modelled in terms of 2 components. A soft coercivity fraction with $\mathrm{B}_{1 / 2}$ of $48 \mathrm{mT}$ and a hard coercivity fraction with $\mathrm{B}_{1 / 2}$ of $708 \mathrm{mT}$. They correspond to magnetite-like and hematite-like phases respectively. The former contributes to 88 to 93\% of the SIRM. The IRM curve for the urban soil shown (Fig. 7b) is best modelled by 3 coercivity components; a soft dominant phase with $\mathrm{B}_{1 / 2}$ of $25 \mathrm{mT}$, an intermediate with $\mathrm{B}_{1 / 2}$ of $182 \mathrm{mT}$ and a hard with $\mathrm{B}_{1 / 2}$ of $794 \mathrm{mT}$. Their model contribution to the SIRM is $70 \%, 13 \%$ and $17 \%$, respectively. The soft and hard components probably correspond to the magnetite-like and hematite-like phases noted for the road dust.

\subsection{Thermal variation of the magnetic susceptibility}

In the heating curves for a typical road dust sample (Fig. 8), the following features are observed:

(i) susceptibility high occurring below ca. 360 to $370^{\circ} \mathrm{C}$;

(ii) a susceptibility rise above $400^{\circ} \mathrm{C}$ leading to a peak at about $540^{\circ} \mathrm{C}$;

(iii) a rapid susceptibility drop, at high temperature, which is estimated by both the 
tangent method and second-derivative method at $585^{\circ} \mathrm{C}$. However, the well-defined linear segment in the calculated inverse susceptibility- temperature curve shows this drop to start at 575 to $580^{\circ} \mathrm{C}$; and

(iv) irreversible susceptibility behaviour upon cooling showing the presence of a single characteristic temperature equivalent to that in (iii).

The IRM data indicate a magnetite-like phase as does the initiation of paramagnetic behaviour at 575 to $580^{\circ} \mathrm{C}$ interpreted to correspond to the Curie temperature of $578^{\circ} \mathrm{C}$ for pure magnetite (Dunlop and Özdemir, 1997). Further support to this comes from the Verwey transition observed at $-155^{\circ} \mathrm{C}$ during the low-temperature warming (Fig. 8c). The susceptibility enhancement within between 400 and $540^{\circ} \mathrm{C}$ (Fig. 8a) is the Hopkinson effect related to a magnetite-like phase (Dunlop and Özdemir, 1997).

Similar features are observed also in the curve for soil sample Hx7 (Fig. 9). The soil samples behave somewhat differently than the road dust in terms of the characteristic temperatures, with irreversible susceptibility upon recycling below $450^{\circ} \mathrm{C}$ (Fig. 9a). Despite noise, there is a well-defined linear segment in the inverse susceptibility-temperature curve starting at $340-350^{\circ} \mathrm{C}$ (Fig. 9a). This is interpreted as decomposition of maghemite, present initially or produced upon heating. Such mineralogical interpretation of this low-temperature rise in soil and road dust susceptibility is consistent with the experimental data of Kosterov (2002). In temperatures above $450^{\circ} \mathrm{C}$, a Curie temperature of $580^{\circ} \mathrm{C}$ is shown by the inverse susceptibility-temperature data, as well as the estimate by the method of two tangents (Fig. 9b). Hence, magnetite is the major ferrimagnetic constituent in the soil samples.

Analysis of susceptibility-temperature runs and IRM acquisition curves (not shown here) obtained from some brick pieces points to a close link between the phase with 340 to $350^{\circ} \mathrm{C}$ decomposition temperatures and the intermediate-coercivity phase with $\mathrm{B}_{1 / 2}$ of $182 \mathrm{mT}$. These features are inferred to be diagnostic of a maghemite-like phase, which is responsible for the unstable susceptibility behaviour upon heating. The maghemite formation might be explained in terms of the rather low temperatures achieved during the preparation of bricks in the kilns such that formation of stable magnetic phases such as magnetite and hematite was not complete (Jordanova et al., 2001). 


\subsection{Microscopic and chemical characterization of magnetic constituents}

Microscopy of the magnetic extract from the road dust reveals basically two morphologies of grains (Fig. 10). Firstly euhedral to anhedral crystalline grains derived from rock sources and secondly spherical grains. These two types are respectively related to lithogenic and anthropogenic inputs, with the latter formed by any combustion. The spherules, of diameter $2-40 \mu \mathrm{m}$, were abundant in the dust from road surface as well as from road-side tree-leaves but absent in the soil samples from sites away from roads (the results from leaves and soils are not detailed here). Therefore, the most likely source of these spherules is the road traffic. These spherules are inferred to be produced in exhausts of vehicles as shown for Tübingen although some of the larger particles, with diameter of tens of microns, may be too large to be explained in this way (Knab et al., 2001, M.W. Hounslow pers. comm.). Judging from the iron content, the lithogenic grains with content of $\mathrm{FeO}_{\text {tot }}$ of about $96.6 \mathrm{wt} \%$ (or $75.1 \mathrm{wt} \%$ of $\mathrm{Fe}$ ) in average are practically indistinguishable from the spherules (Table 1).

$\rightarrow$ Fig. 10

Table 1

\section{Discussion and conclusions}

Magnetic susceptibility measurements on ground and soils in the urban and suburban areas of the Kathmandu Valley reflect the effect of pollution related to vehicular emissions as well as ubiquitous and irregular distribution of construction materials in the soils. Microscopy reveals both lithogenic magnetic grains and anthropogenic magnetic spherules of which the latter are surely derived from vehicular emission (Knab et al. 2001). The presence of lithogenic magnetite is clearly shown by octahedral and rounded to angular magnetic grains. Predominance of minerals with Curie temperature of 575 to $580^{\circ} \mathrm{C}$ in both road dust and soil points to magnetite as both lithogenic mineral grains and spherules of anthropogenic origin. The magnetic spherules and lithogenic grains are practically indistinguishable in terms of $\mathrm{FeO}_{\text {tot }} \mathrm{wt} \%$. Elevated top-soil susceptibilities in the suburban and peripheral parts seem to be due to the emissions from the brick-kilns. Based on these findings, it is suggested that a soil magnetic susceptibility map covering the whole Kathmandu urban area and its peripheries could be prepared and used for rapid identification of pollution "hotspots" that can be further detailed by additional rock-magnetic as well as other non-magnetic environmental studies. Judging from the possibilities of these measurements as providing both non-destructive and rapid application, the magnetic susceptibility technique deserves 
inclusion into the environmental screening and monitoring system of the Kathmandu urban area.

\section{Acknowledgements}

The laboratory work was accomplished at the University of Tübingen during a Georg Forster Research Fellowship granted to PG by Alexander-von-Humboldt Foundation, Germany. The Environmental Unit of the Kathmandu Metropolitan City as well as the Central Department of Geology supported execution of the field-work. Suggestions from reviewers Ken Kodama, John Smith and the Guest editor Mark W. Hounslow were helpful in revising the original manuscript.

\section{References}

Dearing, J., 1999. Environmental Magnetic Susceptibility. Using the Bartington MS2 System (Second Edition).Chi Publishing, England, 54pp.

Devkota, D., 2001. Total and extractable (mobilizable and mobile) heavy metals in the Bagmati river sediment of Kathmandu, Nepal. A Journal of the Environment 6 (7), 34-51.

Dunlop, D.J. and Ozdemir, Ö., 1997. Rock Magnetism: Fundamentals and Frontiers. Cambridge University Press, Cambridge, 573 pp.,

Hoffmann, V., Knab, M., Appel, E., 1999. Magnetic susceptibility mapping of roadside pollution. J. Geochem. Explor. 66, 313-326.

Hanesch, M., Scholger, R., 2002. Mapping of heavy metal loadings in soils by means of magnetic susceptibility measurements. Environ. Geol. 42, 857-870.

Jordanova, N., Petrovsky, E., Kovacheva, M., Jordanova, D., 2001. Factors determining magnetic enhancement of burnt clay from archaeological sites. Journal of Archaeological Science 28, 1137-1148.

Knab, M., Appel, E., Hoffmann, V., 2001. Separation of the anthropogenic portion of heavy metal contents along a highway by means of magnetic susceptibility and fuzzy c-means cluster analysis. Eur. J. Environ. and Eng. Geophys. 6, 125-140.

Kosterov, A., 2002. Low-temperature magnetic hysteresis properties of partially oxidized magnetite. Geophys. J. Int. 149, 796-804.

Kruiver, P.K., Dekkers, M.J., Heslop, D., 2001. Quantification of magnetic coercivity components by the analysis of acquisition curves of isothermal remanent magnetization. Earth Planet. Sci. Lett. 189, 269-276.

Lecoanet, H., Leveque, F., Seguna, S., 1999. Magnetic susceptibility in environmental applications: comparison of field probes. Phys. Earth Planet. Inter. 115, 191-204.

Malinovsky, M., 2001. Air quality management in Kathmandu Valley. A Journal of the Environment 6 (7), 50-57. 
Matzka, J., Maher, B.A., 1999. Magnetic biomonitoring of roadside tree leaves: identification of spatial and temporal variations in vehicle-derived particulates. Atmos. Env. 33, 4565-4569.

Moskowitz, B.M., 1981. Methods for estimating Curie temperatures of titanomagnetites from experimental Js-T data. Earth Planet. Sci. Lett. 53, 84-88.

Muxworthy, A.R., Schmidbauer, E., Petersen, N., 2002. Magnetic properties and Mössbauer spectra of urban atmospheric particulate matter: a case study from Munich, Germany. Geophys. J. Int. 150, 558-570.

NESS, 2001. Air quality database of Nepal. Nepal Environmental and Scientific Services Co., special issue, Kathmandu.

Petrovsky, E., Ellwood B.B., 1999. Magnetic monitoring of pollution of air, land and waters. In: Maher, B.A., Thompson, R. (Eds.), Quaternary Climates, Environments and Magnetism, Cambridge University Press, Cambridge, pp. 279-322.

Petrovský, E., Kapička, A., 2003. Temperature dependence of magnetic susceptibility and determination of Curie (Neel) temperature: are we correct? In: Abstracts, XXII General Assembly of the International Union of Geodesy and Geophysics, Sapporo, A.265.

Pouchou, J.L., Pichoir, F., 1991. Quantitative analysis of homogenous or stratified microvolumes applying the model PAP. In: Heinrich, K.F.J., Newbury, D.E. (Eds.), Electron Probe Quantification, Plenum, New York, pp. 31-75.

Raut, A.K., 2003. Brick kilns in Kathmandu Valley: current status, environmental impacts and future options. Himalayan J. Sciences 1 (1), 59-61.

Sakai, H., Fujii, R., Kuwahara, Y., 2002. Changes in the depositional system of the paleo-Kathmandu lake caused by uplift of the Nepal lesser Himalayas. J. Asian Earth Sci. 20, 267-276.

Shrestha, B., Pradhan, S., 2000. Kathmandu Valley GIS database. ICIMOD, Kathmandu.

Shrestha, R.M., Raut, A.K., 2002. Air Quality Management in Kathmandu. In: Proc. Symp. Better Air Quality in Asian and Pacific Rim Cities (BAQ 2002), Hong Convention and Exhibition Center, Hong Kong, 1-6.

Shu, J., Dearing, J.A., Morse, A.P., Yu, L., Li, C., 2000. Magnetic properties of daily sampled total suspended particulates in Shanghai. Environ. Sci. Technol. 34, 2393-2400.

Tauxe, L., 1998. Paleomagnetic Principles and Practice, Kluwer Academic Publishers, Dordrecht.

Yoshida, M., Gautam. P., 1988. Magnetostratigraphy of Plio-Pleistocene lacustrine deposits in the Kathmandu Valley, central Nepal. Proc. Indian natn. Sci. Acad. 3, 410-417. 


\section{Figure and Table captions (Gautam et al. PCE manuscript $2^{\text {nd }}$ revision)}

Fig. 1. Sketch maps showing the sites of the pilot environmental magnetic study.

a) Index map showing the three districts of Kathmandu Valley. b) The greater Kathmandu urban area comprising Kathmandu and Patan cities (lightly shaded). The light and dark lines indicate the major road network and major rivers marking district boundaries. c) and d): The Ratna Park area at the heart of the Kathmandu city and Kirtipur area investigated in more detail. Filled stars: sites of vertical soil profiles. Hx $n$ are urban area sites and $\mathrm{K}=$ Kirtipur and $\mathrm{B}=$ Balkhu are background sites. Open stars: locations of selected road dust samples $(\mathrm{R} n)$.

Fig. 2. The magnetic susceptibility profile parallel to the ropeway between Machhegaon and Kuleshwar (Fig. 1d). Susceptibility in excess of $30 \times 10^{-5}$ SI seems to arise from periodic baking of the soil due to firing (sites near $2000 \mathrm{~m}$, at the river terrace and at the edge of cultivated areas) or debris of construction material, mainly fired brick pieces (e.g. at the Kirtipur ridge).

Fig. 3. In situ magnetic susceptibility traverses across urban roads at Kirtipur (measured on August 9, 1999 using susceptibility meter Bartington MS2 D-sensor) and the Ring Road at Bafal (measured on May 27, 2001 using susceptibility meter WSLA, AGS China). The locations are indicated as short bars in Fig. 1d. The $28 \mathrm{~km}$ long and $10 \mathrm{~m}$ wide 'Ring Road' (Fig. 1d) is a major urban road encircling most of the Kathmandu urban area and has the highest traffic flow in the city. The Kirtipur Road, just $6.2 \mathrm{~m}$ wide, passing through the university campus and connecting Kathmandu with the satellite town of Kirtipur has a much lower traffic volume. All susceptibility profiles at $2 \mathrm{~m}$ spacing.

Fig. 4. Results of detailed magnetic susceptibility mapping. a) contour map of susceptibility in Ratna Park, center of the urban area. + indicates measurement points. b) Histogram of susceptibility values for Ratna Park and its interpretation in terms of a bimodal lognormal distribution. c). Contour map of susceptibility in the Coronation Garden and University Campus (Kirtipur suburban area).

Fig. 5. Magnetic susceptibility variation along vertical profiles, of soils and sediments, from background areas at Balkhu and Kirtipur (sites B and K in Fig. 1d.). For site K, both volume $(\mathrm{k})$ and mass-specific $(\chi)$ susceptibilities are shown to demonstrate that significant anomalies are identified irrespective of the sample size and susceptibility meters employed. In situ susceptibility measured with MS2F for Balkhu and MS2C (k) and KLY-2 $(\chi)$ for Kirtipur. 
Fig. 6. Magnetic susceptibility variation along vertical sediment and soil profiles in the urban area. Profiles Hx4, Hx7, Hx8 are from the centre of Kathmandu city whereas Hx9 is from Balaju Park situated adjacent to the industrial area (Fig. 1b, cross-hatched). Data on duplicate or triplicate cores (each $35 \mathrm{~mm}$ in diameter) sampled very close to each other are shown using differing line styles.

Fig. 7. Isothermal remanent magnetization curves for the road dust sample (a) and urban soil sample (b). The respective median acquisition field $\left(\mathrm{B}_{1 / 2}\right)$ values modelled, indicated by arrows, as contributing to the curves were determined using Kruiver et al. (2001).

Fig. 8. Thermal variation of the normalized low-field magnetic susceptibility for a typical road dust sample: a) Heating-cooling cycle above room temperature; b) warming from $-194{ }^{\circ} \mathrm{C}$ to $0^{\circ} \mathrm{C}$, and; c) the inverse normalized susceptibility curve and second derivative of the normalized susceptibility near the magnetite Curie point, both calculated from the heating curve shown in a). The beginning of the linear segment in inverse susceptibility curve (at about $578{ }^{\circ} \mathrm{C}$ ) and low-temperature transitions (the observed Verwey transition $\mathrm{Tv}$ at about $-155{ }^{\circ} \mathrm{C}$ and the zero point of crystalline anisotropy constant $\mathrm{T}\left(\mathrm{k}_{1}=0\right)$ at about $\left.-147{ }^{\circ} \mathrm{C}\right)$ point magnetite as the dominant magnetic phase. The characteristic temperatures determined by methods based on tangent fitting and maxima of second derivative (see text) are in fact higher than the actual Curie temperature of magnetite and so are not useful for characterizing the magnetic minerals.

Fig. 9. a) Thermal variation of low-field magnetic susceptibility for urban soil sample (Hx7, from $10 \mathrm{~cm}$ depth). b) Plots of the inverse susceptibility data derived from the first heating and second heating curves in a). Two mineral phases of differing Curie and decomposition temperatures of about $580{ }^{\circ} \mathrm{C}$ and $350{ }^{\circ} \mathrm{C}$ are evident.

Fig. 10. Magnetic grains observed by scanning electron microscopy from a magnetic extract from road dust (sample R11). The numbered grains were analysed by energy dispersive $\mathrm{x}$-ray techniques and their chemistry is shown in Table 1). There are two distinct types of grains; spherules of anthropogenic origin (grains 3 and 13) and non-spherical, euhedral to subhedral grains of lithogenic origin (grains 5, 8, 9, 14-16).

Table 1. Energy dispersive x-ray analytical data for grains in the magnetic extract of the road dust shown in Fig. 10. 

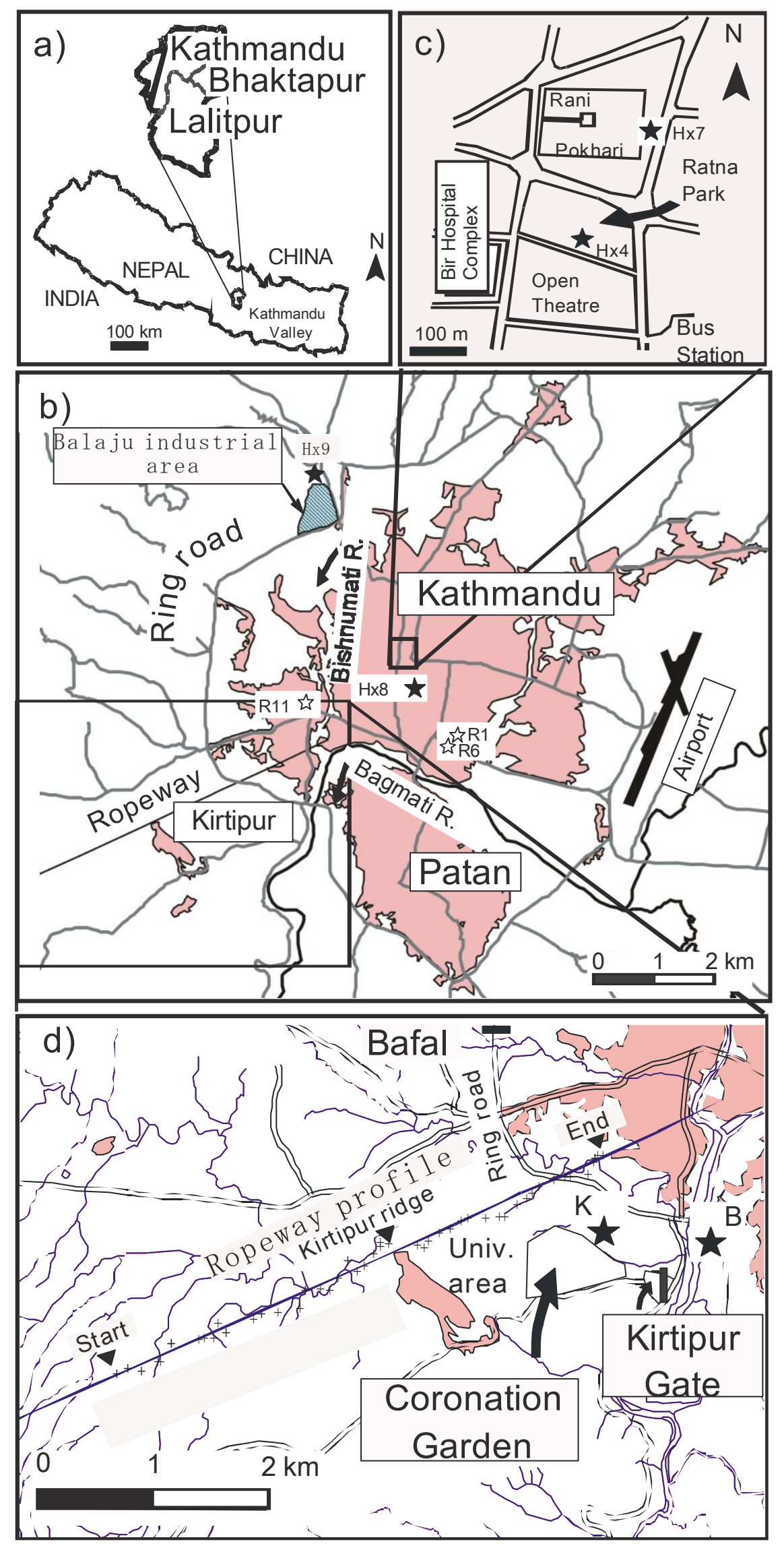

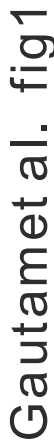




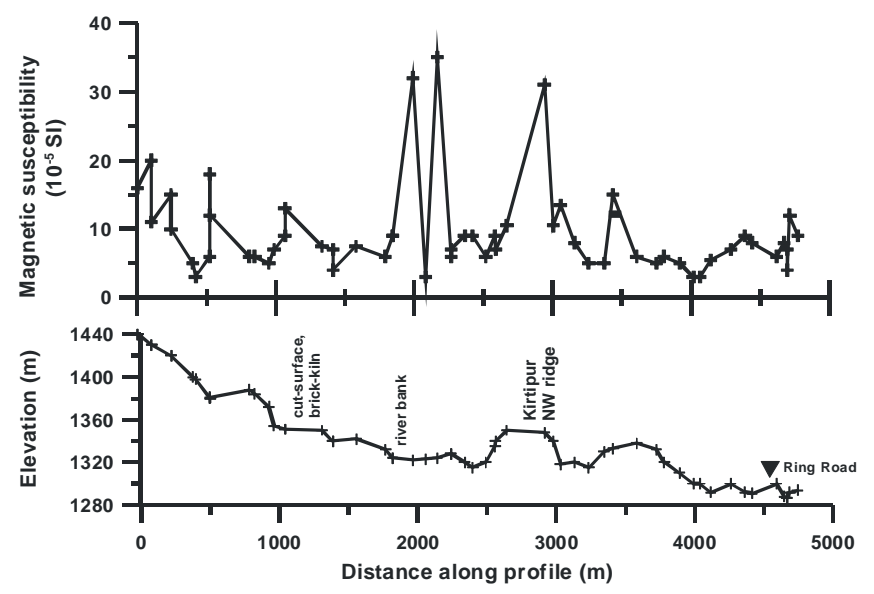

a) University gate, Kirtiur road

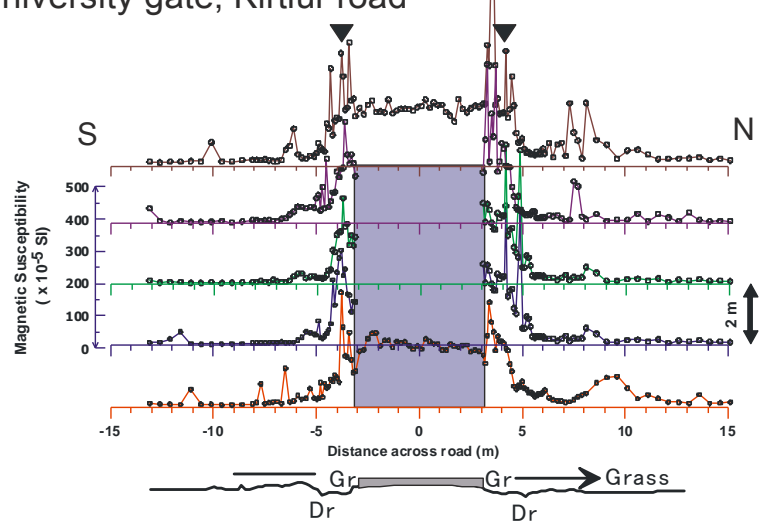

b) Bafal, ring road

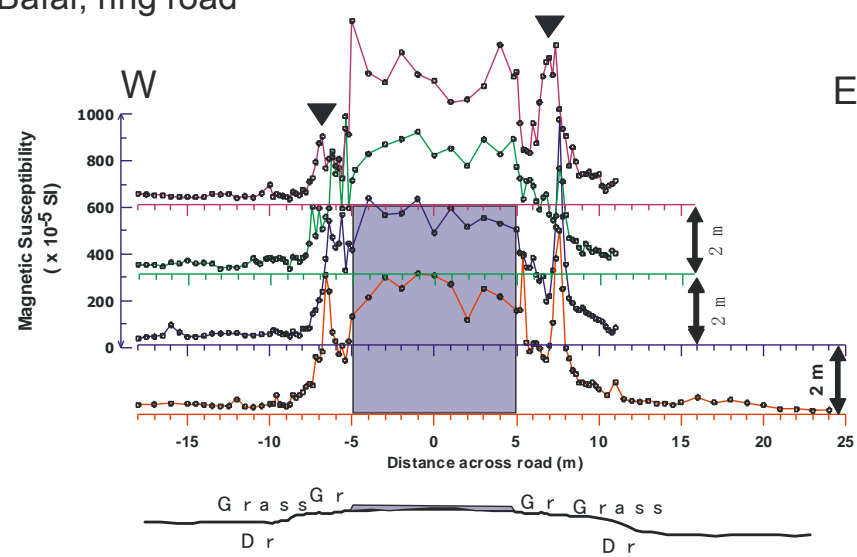

Asphalt-paved road, $\mathrm{Gr}=$ gravel $\mathrm{Dr}=$ drain Approximate locations of the zones of susceptibility enhancement

Gautam et al

Fig. 3 
Locality: Ratna p Park

a)

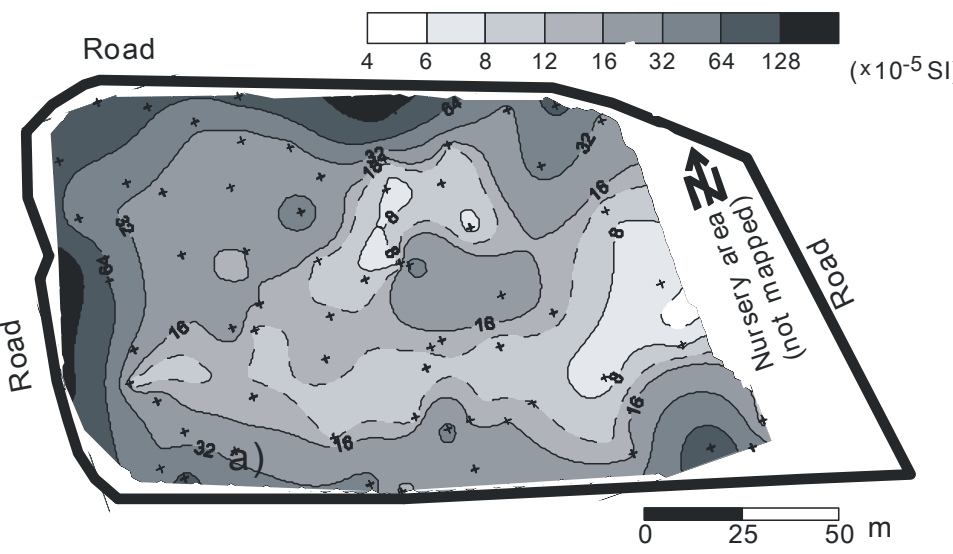

b)

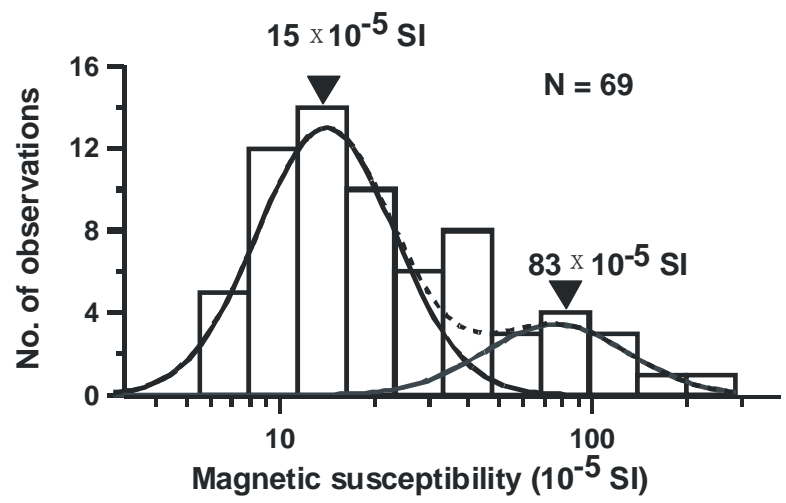

gautametalFig. $4 a b$

c) Locality: Coronation Garden, Kirtipur

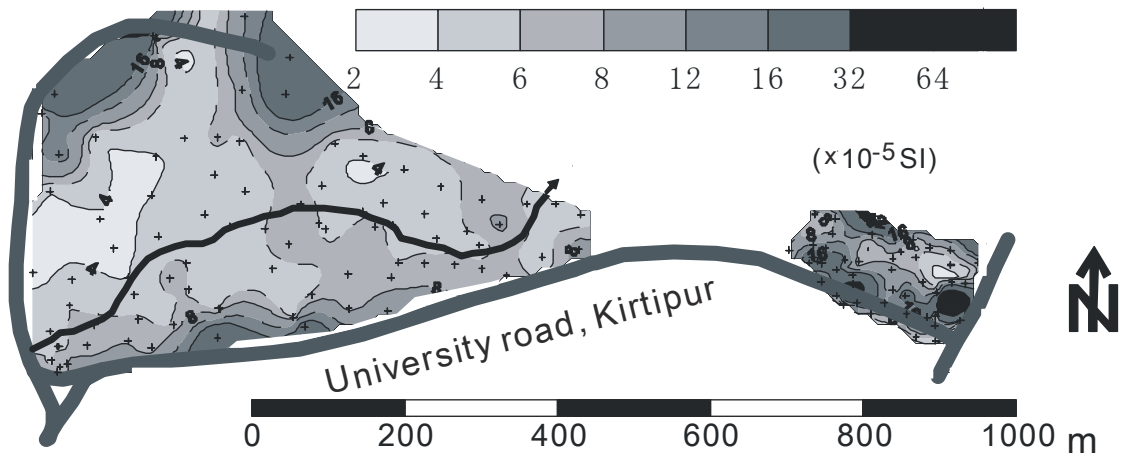

Gautam et al

Fig. $4 \mathrm{c}$ 


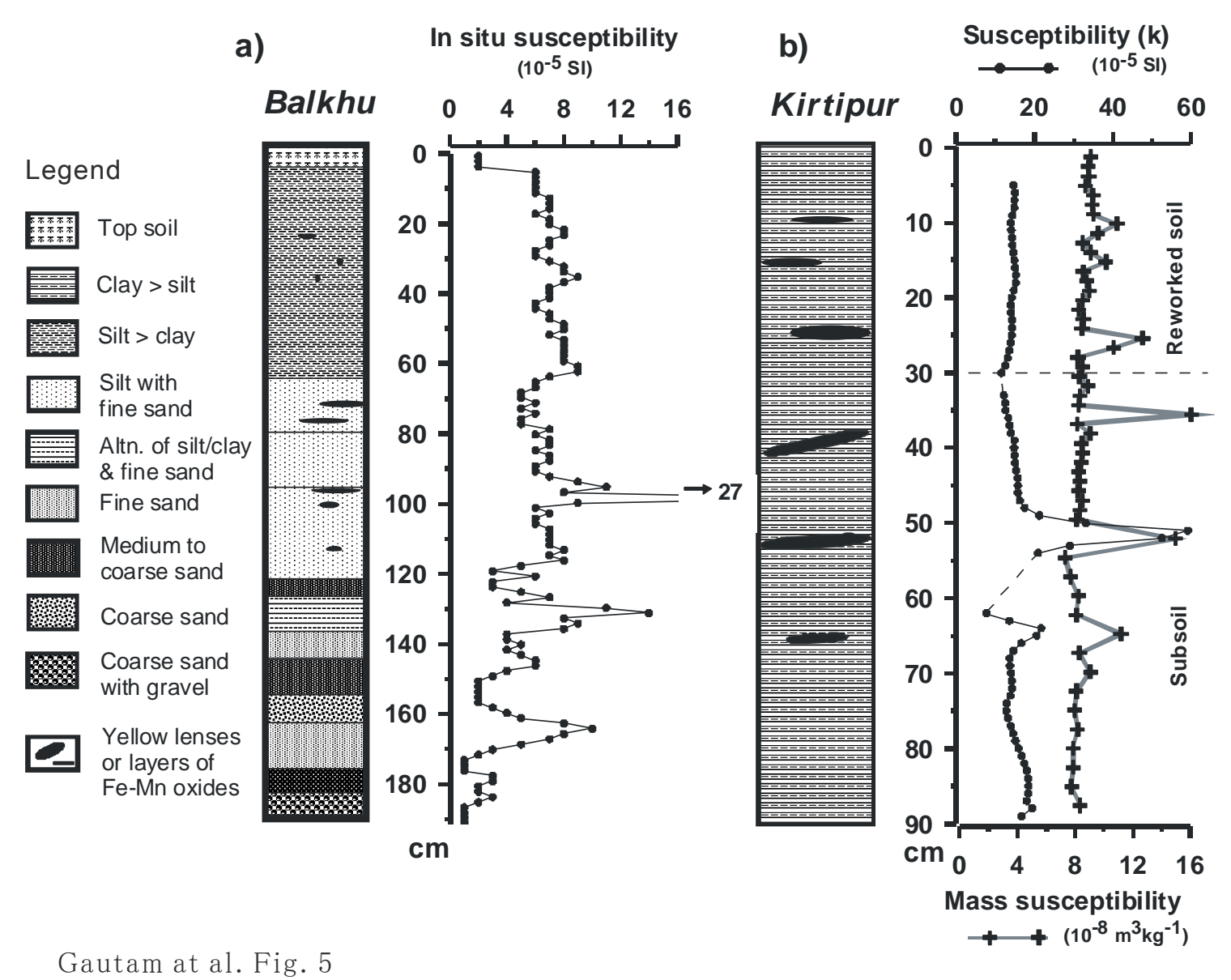

Susceptibility (10-5 $\mathrm{SI})$
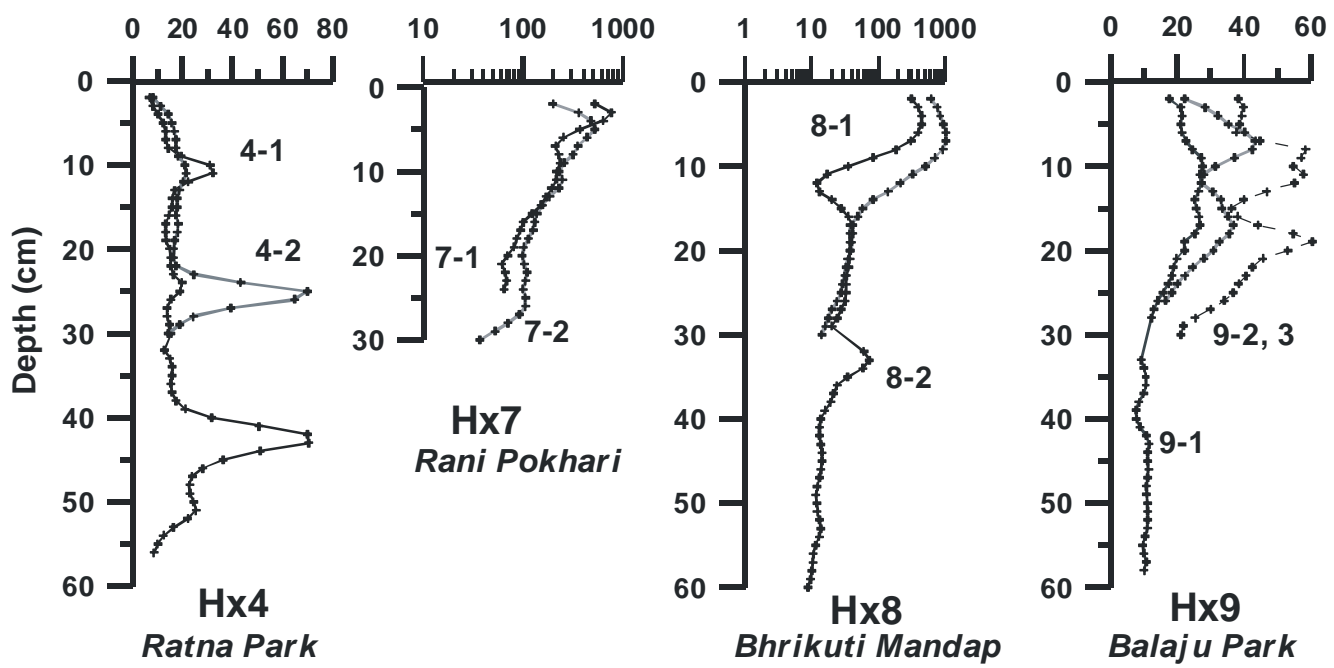

Gautam et al. Fig. 6 
(a)

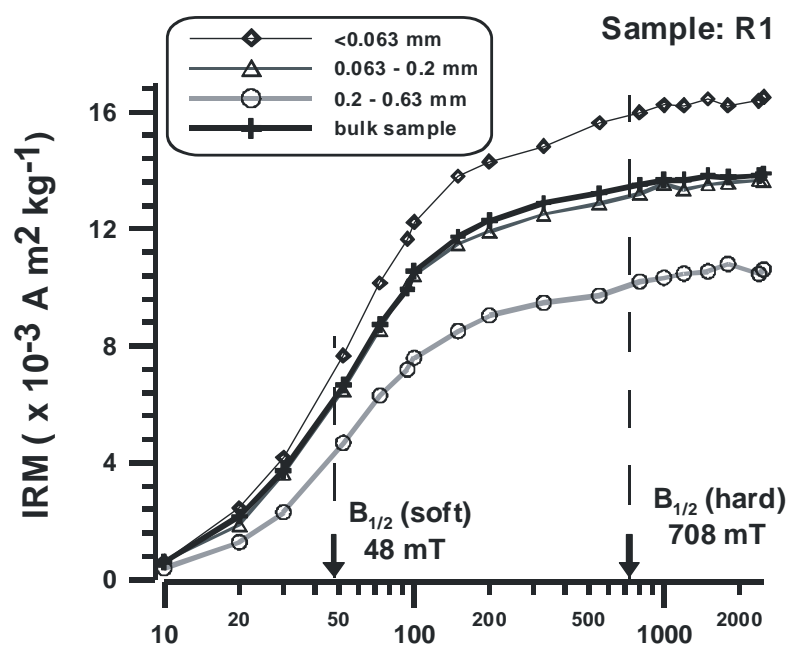

(b)

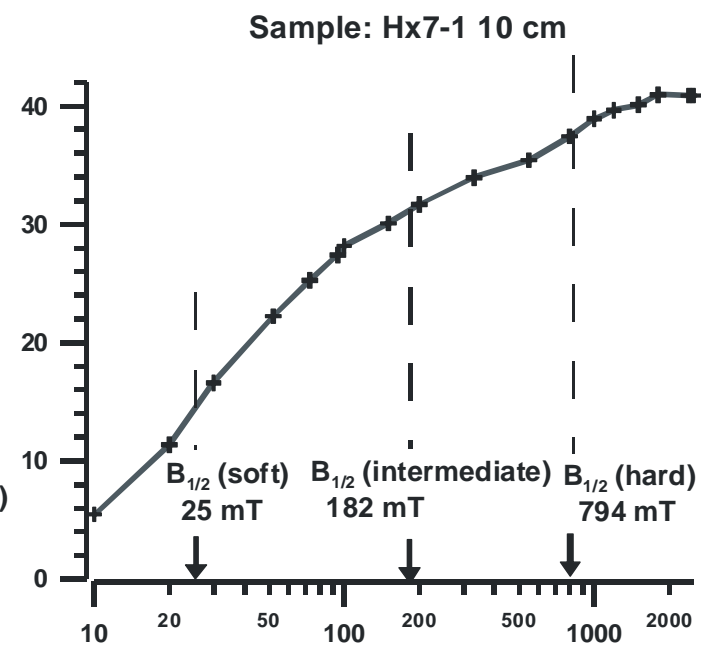

Applied Field (B, mT)

Gautam et al.

Fig. 7 


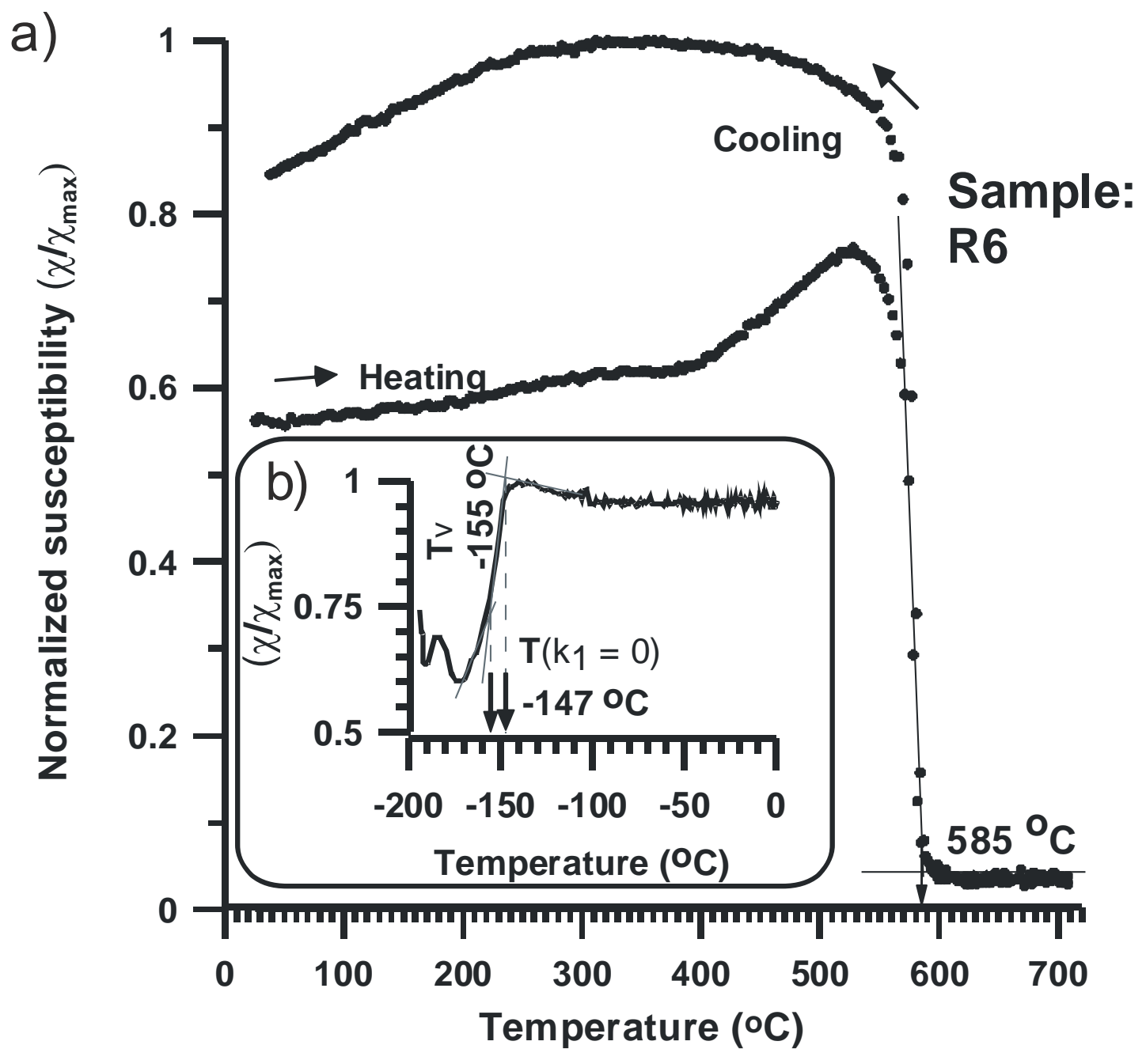

c)

Temperature ( $\left.{ }^{\circ} \mathrm{C}\right)$

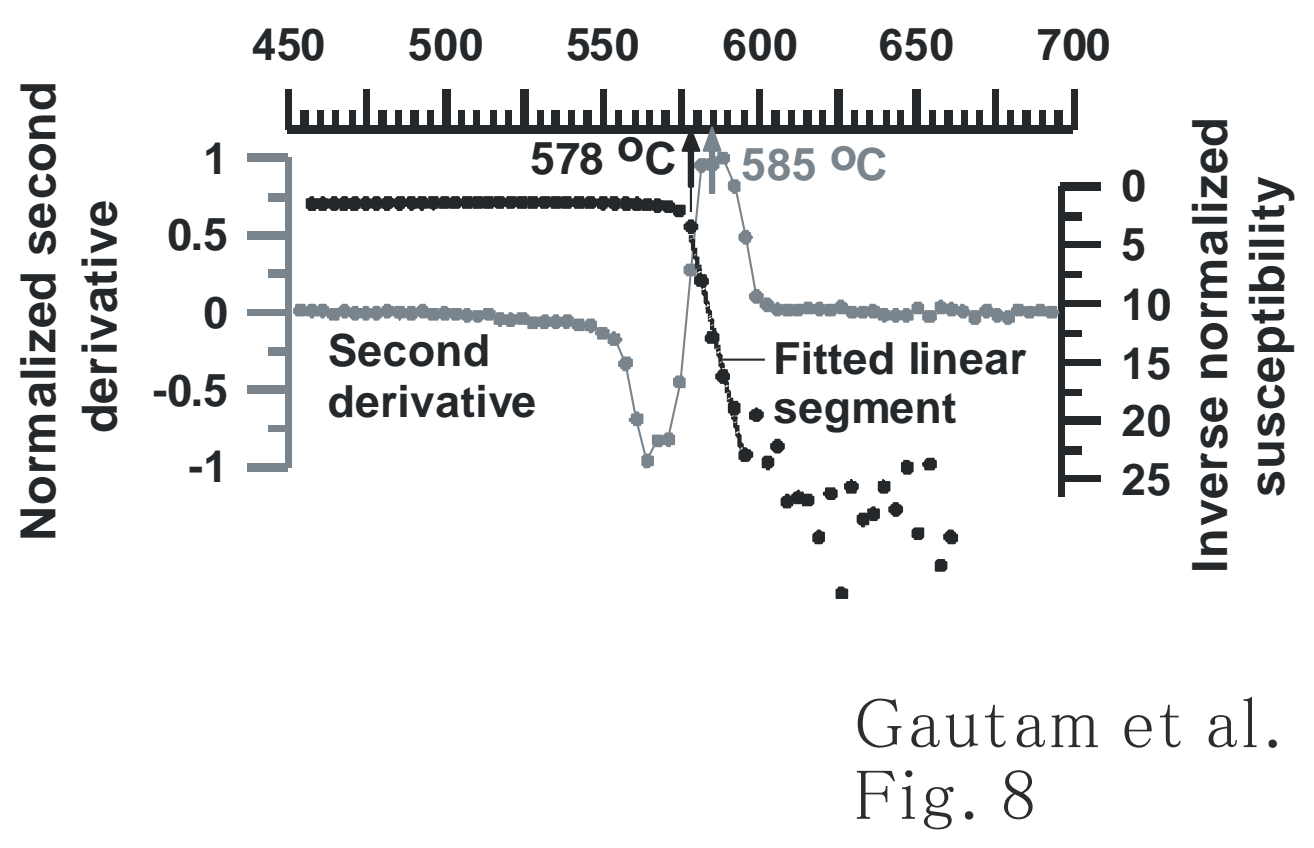




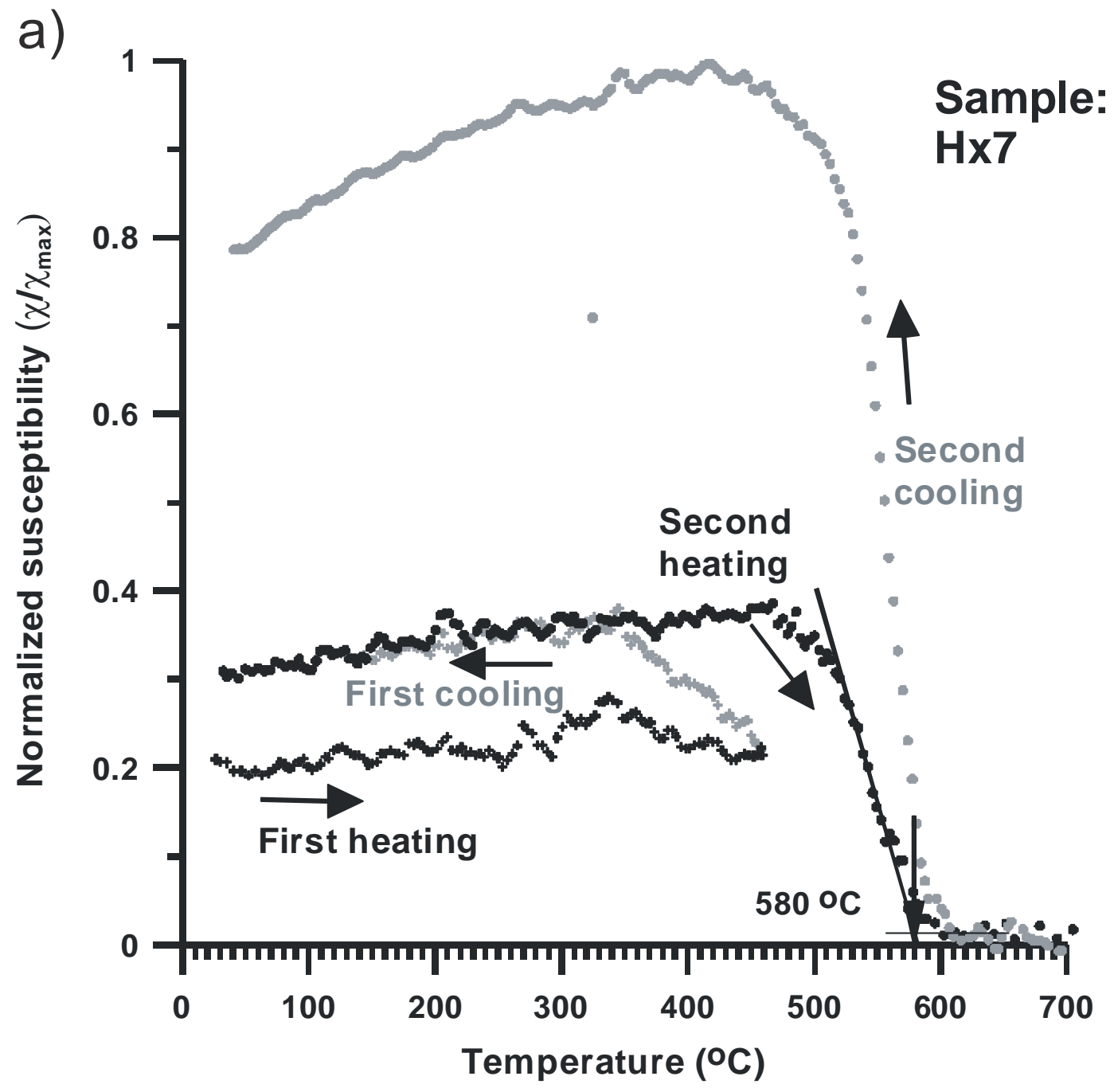

b)

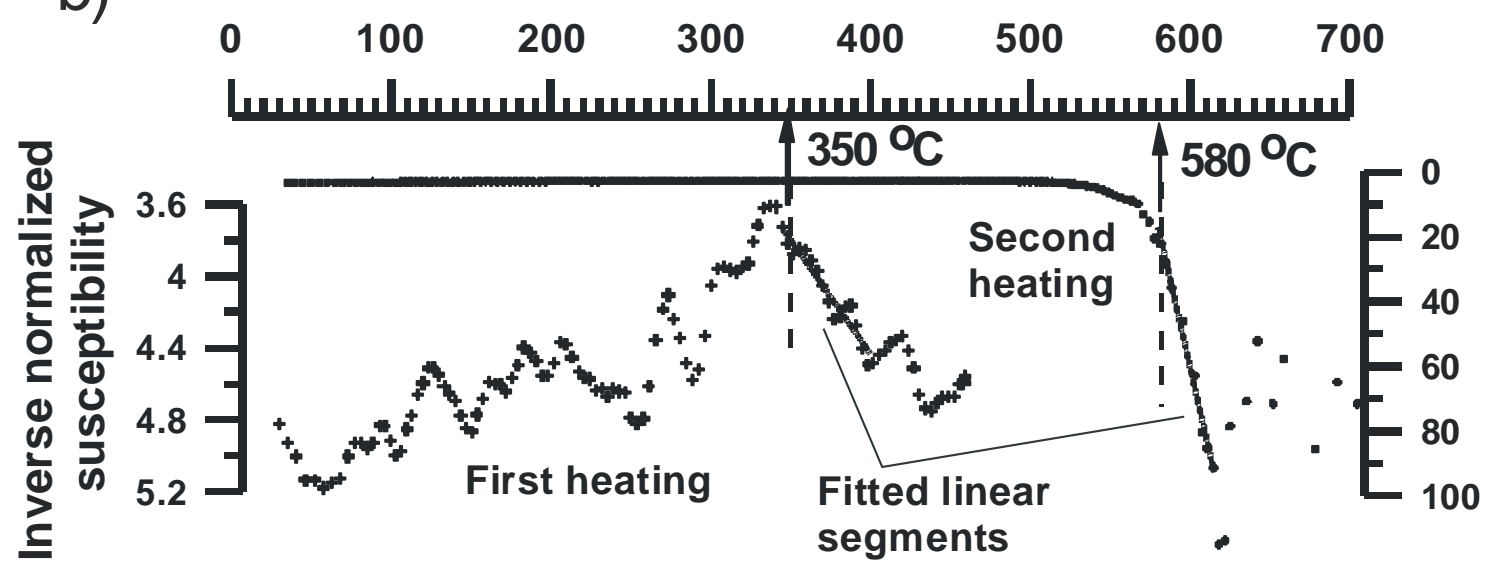

Gautam et al. Fig. 9 
Sample R11
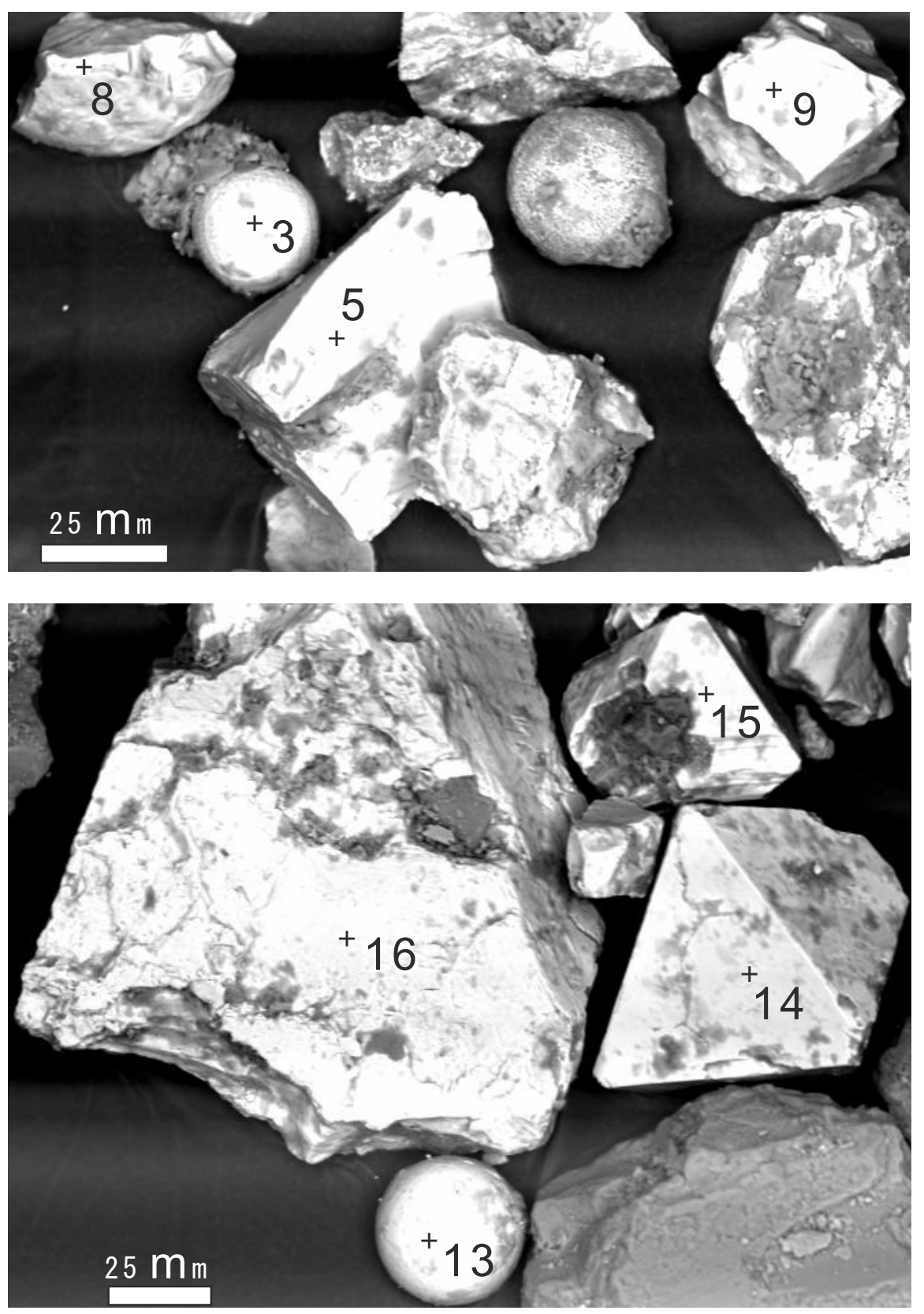

Gautam et al.

Fig. 10 
Table 1

Grain no. $\frac{\text { Anthropogenic grains }}{\mathbf{3}}$

Element (wt\%)

$\mathrm{Fe}$

Al

Si

Co

O

Total
$0.76 \quad 0.84$

0.64

23.08

23.10

100.0

100.0
$74.85 \quad 75.48$

$\begin{array}{ll}0.68 & 0.59\end{array}$

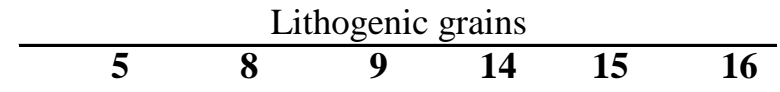

$\begin{array}{llllll}76.63 & 73.25 & 73.82 & 75.90 & 75.33 & 75.67\end{array}$

$\begin{array}{llllll}0.30 & 1.04 & 1.02 & 0.31 & 0.44 & 0.59\end{array}$

$\begin{array}{llllll}0.40 & 1.23 & 1.09 & 0.83 & 1.05 & 0.72\end{array}$

$\begin{array}{lll}0.92 & 0.62\end{array}$

$\begin{array}{llllll}22.67 & 23.56 & 23.46 & 22.96 & 23.17 & 23.02\end{array}$

$\begin{array}{llllll}100.0 & 100.0 & 100.0 & 100.0 & 100.0 & 100.0\end{array}$ 